\title{
Anthropogenic Temperature and Salinity Changes in the Southern Ocean $\mathscr{O}$
}

\author{
William R. Hobbs, ${ }^{\mathrm{a}, \mathrm{b}}$ Christopher RoAch, ${ }^{\mathrm{c}}$ Tilla Roy, ${ }^{\mathrm{d}, \mathrm{e}}$ JeAN-BAPTiste SAllée, ${ }^{\mathrm{c}}$ AND \\ NATHANIEL BINDOFF ${ }^{\mathrm{a}, \mathrm{b}, \mathrm{f}, \mathrm{g}}$ \\ ${ }^{a}$ Australian Antarctic Program Partnership, Institute of Marine and Antarctic Studies, University of Tasmania, Hobart, \\ Tasmania, Australia \\ ${ }^{\mathrm{b}}$ ARC Centre of Excellence for Climate Extremes, Institute for Marine and Antarctic Studies, University of Tasmania, \\ Hobart, Tasmania, Australia \\ ${ }^{\mathrm{c}}$ Sorbonne Université, CNRS, LOCEAN-IPSL Institute, Paris, France \\ ${ }^{\mathrm{d}}$ Département de Géosciences, Ecole Normale Supérieure, Paris, France \\ ${ }^{\mathrm{e}}$ ECOCEANA, Paris, France \\ ${ }^{\mathrm{f}}$ Institute of Marine and Antarctic Studies, University of Tasmania, Hobart, Australia \\ ${ }^{\mathrm{g}}$ CSIRO Oceans and Atmospheres, Hobart, Tasmania, Australia
}

(Manuscript received 15 June 2020, in final form 4 October 2020)

\begin{abstract}
In this study, we compare observed Southern Ocean temperature and salinity changes with the historical simulations from 13 models from phase 5 of the Coupled Model Intercomparison Project (CMIP5), using an optimal fingerprinting framework. We show that there is an unequivocal greenhouse gas-forced warming in the Southern Ocean. This warming is strongest in the Subantarctic Mode Waters but is also detectable in denser water masses, which has not been shown in previous studies. We also find greenhouse gas-forced salinity changes, most notably a freshening of Antarctic Intermediate Waters. Our analysis also shows that non-greenhouse gas anthropogenic forcings-anthropogenic aerosols and stratospheric ozone depletion-have played an important role in mitigating the Southern Ocean's warming. However, the detectability of these responses using optimal fingerprinting is model dependent, and this result is therefore not as robust as for the greenhouse gas response.
\end{abstract}

KEYWORDS: Ocean; Southern Ocean; Climate change; Coupled models; Model comparison

\section{Introduction}

The Southern Ocean has a disproportionally large impact on the global climate system through its prominent role in the ocean uptake of anthropogenic heat and carbon (Rintoul and Church 2002). Consistent with observation-based estimates, models indicate that the Southern Ocean south of $30^{\circ} \mathrm{S}$ was responsible for $43 \% \pm 3 \%$ of global ocean anthropogenic $\mathrm{CO}_{2}$ uptake from 1861 to 2005 , and $75 \% \pm 22 \%$ of anthropogenic heat uptake over the same period (Frolicher et al. 2015); since 2006 the Southern Ocean has accounted for about $65 \%$ of observed heat uptake (Roemmich et al. 2015; Wijffels et al. 2016). This uptake occurs in large part because of the Southern Ocean's strong connection between the surface and deep ocean, allowing an unusually high exchange of heat and gases between the deep ocean and the atmosphere. Much of the world's deep waters upwell in the mid- to high-latitude Southern Ocean as Circumpolar Deep Water (CDW), primarily under the combined action of wind stress (Marshall and Speer 2012; Rintoul and Naveira Garabato 2013; Morrison et al. 2015), eddies (Tamsitt et al. 2017), and air-sea ice-ocean

Supplemental information related to this paper is available at the Journals Online website: https://doi.org/10.1175/JCLI-D-200454.s1.

Corresponding author: William Richard Hobbs, whobbs@utas. edu.au buoyancy forcing (Abernathey et al. 2016; Pellichero et al. 2018). The lighter branch of this CDW is transported northward and transformed into Antarctic Intermediate Water (AAIW) and Subantarctic Mode Water (SAMW), important water masses for the uptake of anthropogenic heat and carbon (Sallée et al. 2012); the denser branch is transported southward toward the Antarctic continental shelf, where it is converted through sea ice formation into Antarctic Bottom Water (AABW), the coldest, densest water mass on the planet (Orsi et al. 1999; Pellichero et al. 2018).

The complexity of this overturning system is reflected in observed changes in temperature and salinity in the Southern Ocean. Previous studies have identified a very clear, detectable global ocean warming in response to anthropogenic greenhouse gases (Bilbao et al. 2019; Tokarska et al. 2019), but given its essential role in the global climate the Southern Ocean merits specific analysis. There is little evidence of a detectable anthropogenic change at the surface of the high-latitude Southern Ocean (south of $60^{\circ}$ S) (Polvani and Smith 2013; Zunz et al. 2013; Fan et al. 2014; Armour et al. 2016; Hobbs et al. 2016b), but farther north there has been a warming and freshening of Mode and Intermediate Waters (Wong et al. 1999; Bindoff and McDougall 2000; Aoki et al. 2005; Meijers et al. 2011; Gao et al. 2018). This is thought to be due to the meridional overturning circulation, which transports surface warming northward into Mode and Intermediate Water formation regions, and replenishes the high-latitude surface with old CDW, resulting in a delay in anthropogenic surface warming at mid- to high latitudes, and a convergence of heat 
farther north (Marshall et al. 2014; Armour et al. 2016). While the surface high-latitude Southern Ocean surface may have a delayed warming, the same is not true at depth. Observations indicate an extensive warming and salinification of waters on the west Antarctic continental shelf and in the circumpolar waters off the shelf since the mid-twentieth century (Gille 2002; Schmidtko et al. 2014), and deeper still there has been an observed warming and freshening of AABW (Purkey and Johnson 2013; Purkey et al. 2014; van Wijk and Rintoul 2014).

A number of studies have compared observed changes with simulated anthropogenic responses. Fyfe (2006) showed that the 1930-89 middepth warming (700-1100 m) of the Southern Ocean was only replicated in climate models that included anthropogenic greenhouse gas forcing, while Banks and Bindoff (2003) found an anthropogenic cooling and freshening of Antarctic Intermediate Waters in isopycnal coordinates. However, it is important to place these observed changes in the context of anthropogenic forcing and natural variability. Relative to the other ocean basins, the Southern Ocean's variability occurs at long time scales (10-50 yr; Monselesan et al. 2015), and hence observed changes since the mid- to late twentieth century may be aliased by multidecadal variability. Recently, Swart et al. (2018) published the first detection and attribution study to formally demonstrate that temperature and salinity changes in the Southern Ocean are forced by anthropogenic greenhouse gas (GHG) emissions, with a further contribution to observed temperature changes from stratospheric ozone depletion. That study used a single-model large-ensemble approach to examine temperature and salinity changes in the domain observed by the standard Argo floats, (i.e., north of $60^{\circ} \mathrm{S}$ and $2000 \mathrm{~m}$ or shallower) (Roemmich and Gilson 2009).

In this work, we extend the Swart et al. (2018, hereinafter SW18) analysis by 1) considering observations of the full-depth and entire latitudinal domain south of $30^{\circ} \mathrm{S}$, specifically to ascertain whether there is a detectable signal anthropogenic signal in waters denser than those considered in SW18, and 2) performing the analysis using a number of models selected from the Coupled Model Intercomparison Project version 5 (CMIP5: Taylor et al. 2012) on the basis of their representation of Southern Ocean water masses to ascertain the degree of model dependence on the results. We find that, consistent with SW18, there is overwhelming evidence for a GHG-forced warming of the SAMW/AAIW water masses since the late twentieth century, and furthermore there is good evidence for a detectable GHG warming in deeper water masses across models. However, the detectability of anthropogenic influence on salinity changes is more model dependent.

\section{Data and methods}

\section{a. Observations}

Observed changes in Southern Ocean temperature and salinity are represented here by full-depth conductivity-temperature-depth (CTD) profiles from the World Ocean Database (WOD). We use all available profiles south of $30^{\circ} \mathrm{S}$, for the time periods 1966-75 and 1996-2005 inclusive, with a WOD quality control flag of 0 or 1 , indicating the highest data quality. This period covers the start of a reasonable consistent sampling level (from the mid-
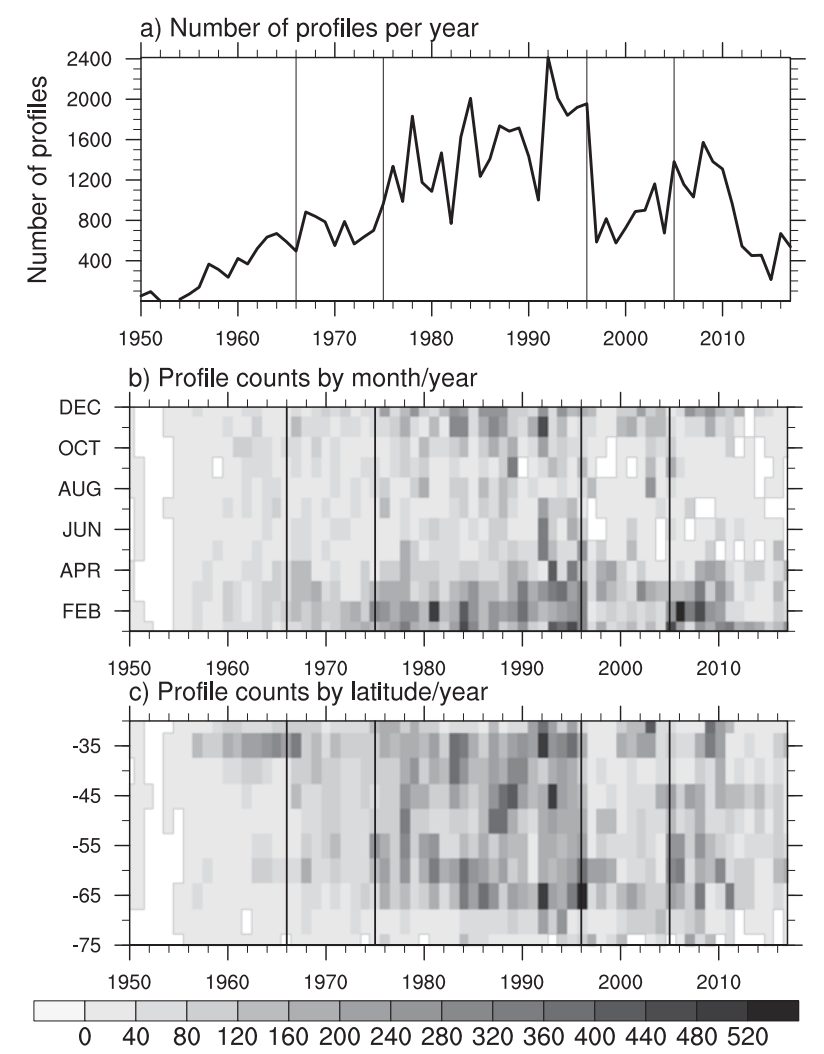

FIG. 1. Temporal and spatial distribution of World Ocean Database profiles in the study domain (i.e., south of $30^{\circ} \mathrm{S}$ ): (a) total number of profiles per year, (b) number of profiles by year and month, and (c) number of profiles by year and latitude. Vertical lines show the start and end of the study averaging periods.

1960s), to the end of the CMIP5 "historical" simulations (Fig. 1). SW18 used climatologies derived from Argo profiling floats, and therefore was restricted to the Southern Ocean domain covered by the regular Argo dataset (i.e., north of $60^{\circ} \mathrm{S}$, and 2000-m depth or shallower). We use ship-based profiles here, despite their more limited data coverage and seasonal bias toward summer observations, to allow an analysis of changes in deeper/higher-latitude water masses.

The change detection pattern used in this study is the zonal mean difference in potential temperature $T$ and absolute salinity $S_{\mathrm{A}}$, between the two 10 -yr time periods $1966-75$ and 1996-2005, as a function of depth and latitude. The values of $T$ and $S_{\mathrm{A}}$ were calculated from the observed conservative temperature $\Theta$ and practical salinity, respectively, using the TEOS10 equation of state (IOC et al. 2010). To remove seasonal and spatial dependence, the observations were converted to anomalies by subtracting a climatological mean for each profile's month and location estimated from the Southern Ocean State Estimate (Mazloff et al. 2010). This state estimate was chosen in spite of its relatively short time period (2005-10) because of its high spatial resolution. To construct zonal/ decadal means for each decade, the $T$ and $S_{\mathrm{A}}$ anomaly profiles were binned into $2^{\circ}$ latitude $\times 3^{\circ}$ longitude boxes and averaged across each latitude; bins with no profiles were set to a 
missing value. The change pattern was calculated by simply subtracting the earlier decade/zonal mean from the latter. The standard WOD vertical grid has higher resolution near the surface than at depth; therefore, to avoid weighting the optimal fingerprint results toward near-surface data changes, the zonal means were regridded to a 100 -m constant-vertical-resolution grid.

\section{b. Model data}

In this analysis, we used output from the CMIP5 historical, historicalGHG, and historicalNat experiments to represent the Southern Ocean response to all forcings, greenhouse gases only, and natural forcings (i.e., solar and volcanic) respectively (Taylor et al. 2012). A residual pattern of response was derived by subtracting the GHG pattern from the All-forcings pattern. Assuming that the All-forcings response is a linear sum of the individual forcings, this residual represents the contribution from land-use change, anthropogenic aerosols, and stratospheric ozone depletion. These forcings could not be separated since very few modeling groups performed experiments with these as single forcings, although in practice the widespread effect of land use change in the ocean-dominated Southern Hemisphere is expected to be minimal. We note that SW18 found little contribution from anthropogenic aerosols, which would imply that the residual is likely to largely represent the impact of stratospheric ozone depletion, an important Southern Ocean forcing (e.g., Bitz and Polvani 2012; Previdi and Polvani 2014). However, it must be noted that CMIP5 models also show that anthropogenic aerosols may impose a surface cooling of the subtropical Southern Hemisphere ocean (Cowan et al. 2013). Since our framework is unable to rigorously separate ozone depletion and aerosol effects, we use the somewhat cumbersome term "non-GHG anthropogenic forcings." We also used output from the pre-industrial control simulation (piControl), to represent unforced internal variability, and to correct for model drift in the forced experiments (Hobbs et al. 2016a).

We used simulations from 13 models in the CMIP5 archive, selected on the basis of length of their piControl simulations (a minimum of 400 years, representing $\geq 10$ nonoverlapping $40-\mathrm{yr}$ periods, or realizations), the number of "historical" members (at least 3), and the representation of Southern Ocean watermass mean states (SAMW, AAIW, CDW, and AABW). The latter selection is described in detail in the online supplemental material, but broadly we applied a density classification on all 23 CMIP5 models with sufficient piControl lengths/historical ensembles, following the approach of Roy et al. (2020, manuscript submitted to J. Climate) that uses salinity and potential vorticity to objectively identify each water mass on the models' native climatologies, derived in this case from the 1965-2005 mean of one "historical" ensemble member from each model. The watermass mean temperature, salinity, and volume south of $30^{\circ} \mathrm{S}$ were compared with the 2009 CSIRO Atlas of Regional Seas climatology (Ridgway et al. 2002), and all models with a reasonable mean representation of these water masses are included. This approach is taken because of the difficulty some models have in achieving watermass characteristics that are similar to the observed mean fields, and thus affects the perturbations and their interpretation. Note that the
CanESM2 simulations have biases in SAMW, AAIW, and CDW that are similar to several rejected models, but are included in this analysis as a direct comparison to SW18. Where the selected models have very close similarity, both in their physics and model grid, we have clustered the models into groups (Table 1), in which case the members from both models were included in the group ensemble mean for each forced experiment, and both models' piControl 40-yr realizations were included in a single piControl distribution. This grouping approach partially addresses the problem of intermodel dependence between coupled models with similar components (Knutti et al. 2013), and also increases the number of available ensemble members over which anthropogenically forced experiments can be averaged, reducing the statistical contamination of the estimated response patterns by internal variability.

Unless stated otherwise, the model plots in this paper are derived using each model's full grid data at monthly temporal resolution. However, full-grid data were not used in the Optimal Fingerprint analysis described in section 2c, due to the uneven spatial distribution and seasonal bias in the observed profiles. To ensure a fair comparison between the models and observations, profiles were subsampled from the model grid cell and month matching the location and date of each observed profile. (For the piControl realizations, the first year of each 40-yr period was taken to be 1966, and spatial/temporal subsampling was performed in exactly same way). The model profiles were converted to anomalies by calculating a mean value for each profile across each model's piControl simulations, so removing seasonal and spatial bias. This also removes any spurious temporal dependence (i.e., model drift), since any structural signal across the time distribution of the profiles is change, which should be zero averaged across an equilibrium (i.e., piControl) climate; therefore, any nonzero change across the time dimension when averaged over all the realizations across the complete piControl simulation can be assumed to be drift. Where multiple models have been merged into a group, anomalies for each model within the group were calculated with respect to that model's piControl simulation, before ensemble-averaging across the models in the group. Following this procedure, the subsampled model data were converted into zonal mean temperature and salinity change patterns in exactly the same fashion as described for the observations in section $2 \mathrm{a}$.

\section{c. Optimal fingerprinting}

The detection and attribution analysis in this study relies on optimal fingerprinting (Hasselmann 1993), a widely used method of attributing changes in the climate's mean state. Following Hegerl et al. (2009), the term "detection" is used to formally to refer to the identification of a climate change signal that is outside the range of internal variability, and "attribution" to refer to the process of attributing that change to an individual forcing (e.g., anthropogenic greenhouse gases or ozone-depleting chemicals). The method is described in many papers (Allen and Tett 1999; Allen and Stott 2003; Bindoff et al. 2013), so we give only a simplified overview here, with an illustrative example in the online supplemental material. The 
TABLE 1. Summary of CMIP5 models used in this study, showing model generic name (where similar models have been merged), individual model name, citation of model description, number of ensemble members by experiment, and number of independent realizations (i.e., independent 40-yr segments) in each model's piControl simulation. Expansions of model acronyms are available online (https://www.ametsoc.org/PubsAcronymList).

\begin{tabular}{|c|c|c|c|c|c|c|}
\hline Group name & Model name(s) & Reference & $\begin{array}{c}\text { Historical } \\
\text { members }\end{array}$ & $\begin{array}{c}\text { HistoricalGHG } \\
\text { members }\end{array}$ & $\begin{array}{c}\text { HistoricalNat } \\
\text { members }\end{array}$ & $\begin{array}{l}\text { piControl } \\
\text { realizations }\end{array}$ \\
\hline \multirow[t]{3}{*}{ ACCESS1 } & ACCESS1.0 & Bi et al. (2013) & 3 & 0 & 0 & 12 \\
\hline & ACCESS1.3 & Bi et al. (2013) & 3 & 3 & 3 & 12 \\
\hline & Total & Bi et al. (2013) & 6 & 3 & 3 & 24 \\
\hline CanESM2 & CanESM2 & Arora et al. (2011) & 5 & 5 & 5 & 24 \\
\hline CSIRO Mk3.6.0 & CSIRO Mk3.6.0 & Jeffrey et al. (2013) & 9 & 10 & 10 & 12 \\
\hline FIO-ESM & FIO-ESM & Qiao et al. (2013) & 3 & 0 & 0 & 20 \\
\hline FGOALS-s2 & FGOALS-s2 & Bao et al. (2013) & 3 & 0 & 0 & 12 \\
\hline GFDL CM3 & GFDL CM3 & Griffies et al. (2011) & 5 & 3 & 3 & 12 \\
\hline \multirow[t]{3}{*}{ MIROC-ESM } & MIROC-ESM & Watanabe et al. (2011) & 3 & 3 & 3 & 15 \\
\hline & $\begin{array}{l}\text { MIROC- } \\
\text { ESM-CHEM }\end{array}$ & Watanabe et al. (2011) & 1 & 1 & 1 & 5 \\
\hline & Total & Watanabe et al. (2011) & 4 & 4 & 4 & 20 \\
\hline \multirow[t]{3}{*}{ MPI-ESM-LR } & MPI-ESM-LR & Jungclaus et al. (2013) & 3 & 0 & 0 & 25 \\
\hline & MPI-ESM-P & Jungclaus et al. (2013) & 2 & 0 & 0 & 28 \\
\hline & Total & Jungclaus et al. (2013) & 5 & 0 & 0 & 52 \\
\hline MPI-ESM-MR & MPI-ESM-MR & Jungclaus et al. (2013) & 3 & 0 & 0 & 24 \\
\hline MRI-CGCM3 & MRI-CGCM3 & Yukimoto et al. (2012) & 5 & 1 & 1 & 12 \\
\hline
\end{tabular}

fundamental principle is that an observed change pattern (in this case, zonal mean Southern Ocean temperature and salinity change) may be decomposed into a sum of responses to external forcing, plus internal variability. The responses are estimated by an ensemble of climate model simulations forced by one or several realistic historical climate forcings, the ensemble being necessary to remove the impact of internal variability from the estimated response. Internal variability is represented by a long control simulation with no transient forcing. This control simulation is divided into segments known as "pseudo observations" with the same time length as the analysis period.

The simulated forced response patterns are regressed against the observed change, to give a "best fit" scaling factor; in this analysis we use single regression against the All-forcings response for the detection analysis, and multiple linear regression against the GHG-only, Natural-only, and residual responses for the attribution analysis. The regression is repeated between the forced responses and each of the 40-yr control realizations; this gives a distribution of scaling factors possible in the case of no external forcing, from which a confidence interval can be estimated. The null hypothesis is that there is no forced climate change in the observations (i.e., the scaling factor $=0$ ); hence, where the scaling factor and its confidence interval do not include 0 , the null hypothesis can be rejected, and that signal is detectable. It may be useful to note that the confidence intervals are not just set by the simulated internal variability, but also by the magnitude of the simulated response to forcing. A response that is weak will allow for large scaling factors when applied to the unforced control run, and therefore a large confidence interval.

For most regional changes the signal (i.e., the forced response) is small relative to noise (i.e., internal variability). The optimization addresses this by dividing the observed and simulated patterns by the noise covariance matrix of the control pseudo observations, weighting the patterns toward modes of variability with relatively low noise; the scaling factors are estimated from these optimized fingerprints rather than from the physical patterns.

In practice, the real noise covariance matrix is rarely invertible, so a Moore-Penrose pseudoinverse is used that utilizes empirical orthogonal functions (EOFs) estimated from the control simulation. [In this analysis, following best practice (Hegerl et al. 2009) we estimate the noise covariance matrix from a separate distribution of control run that overlaps the distribution of pseudo observations used to estimate scaling factor confidence bounds; this means that there is some independence between the covariance matrix and the confidence interval estimate, while retaining a sufficient number of control realizations for both distributions.] The results may be sensitive to the number of EOFs retained, with the risk of false detection if too many EOFs are included. We use here a consistency test proposed by Allen and Tett (1999), whereby the response scaled by the best-fit scaling factor is removed from the observed pattern, and the residual-which theoretically represents the contribution from internal variability-is tested to be statistically consistent with the model noise covariance matrix. The truncation level (i.e., the number of EOFs retained) is based on the maximum number of retained EOFs that pass this test. (This can also be thought of as identifying the modes of variability that the model simulates and eliminating higher-order modes in the observations that the model cannot represent-for example, subgrid-scale modes). We provide an example of the optimal fingerprint procedure for ACCESS1 in the online supplemental material.

Where a number of truncation levels pass this test (as is usually the case), we selected the truncation level that showed a detectable signal (if there is one), and with a scaling factor closest to 1 (since 1 implies that model agrees very well with the 
observations). For the attribution case where there are two scaling factors (GHG and non-GHG), we select the case in which both signals are detectable or, if there are none, then the case in which one of the signals is detectable and in which their root-mean-square difference from 1 is minimized.

\section{Results}

\section{a. Observed and simulated changes}

Figures 2 and 3 show the observed and simulated changes in potential temperature and absolute salinity, respectively. The observations indicate a warming in almost all of the domain, from the surface to the bottom, except in the near-surface high latitudes (south of $60^{\circ} \mathrm{S}$ ) that show a distinct cooling, a pattern that is consistent with post-2005 observed changes (Bronselaer et al. 2020). The models indicate an overall warming response that is most concentrated in the SAMW/AAIW regions, as described in previous studies (Armour et al. 2016; SW18). In agreement with the observations, the models also show a warming in the CDW density class, and some (but not all) replicate the observed warming of Bottom Water (Purkey and Johnson 2013; van Wijk and Rintoul 2014). The warming everywhere is stronger in the GHG-only experiments than the All-forcings, which indicates that the warming is forced by anthropogenic GHG, somewhat mitigated by the non-GHG forcings. This is confirmed by the ALL - GHG - NAT pattern, which indicates a non-GHG anthropogenic cooling that is significant relative to the control-run internal variability.

The observed salinity changes (Fig. 3) indicate a freshening over most of the domain, including $\mathrm{AABW}$, with a notable salinification in the SAMW density class. The simulated salinity responses are more spatially heterogeneous than the temperature response, but are broadly consistent with previous observation analyses of late-twentieth-century salinity change (Boyer et al. 2005; Durack and Wijffels 2010), with a freshening in the upper $2000 \mathrm{~m}$ south of $45^{\circ} \mathrm{S}$ and a weak salinification in the upper $500 \mathrm{~m}$ farther north. The models largely show a freshening of the AAIW that is similar in the GHG and Allforcings experiments, indicating GHG as the dominant forcing. Some of the models show a salinification of the SAMW under All and GHG forcings, but the signal is by no means robust across all models. Most of the models show a clear salinification of the CDW density class, with the clearest signal being in the lower CDW and the boundary with AABW (Sallée et al. 2013); comparison between the All-forcings and GHG responses suggest that this is primarily due to GHG forcing.

At the Antarctic coastline, there is a notable observed freshening in the upper $1000 \mathrm{~m}$, capped by a salinification at the surface; this salinification is matched by a cooling in the same region (Fig. 2). The coastal subsurface freshening is reproduced by some models under All-forcings and is evident in previous analyses of observations (Boyer et al. 2005; Durack and Wijffels 2010). However, the surface salinification is not robustly shown in previous observational studies; it is weakly present in the Boyer et al. (2005) data but not in the Durack and Wijffels (2010) zonal mean [although there are longitudes of coastal surface salinification in Durack and Wijffels (2010)].
There is a surface salinification in an estimate of later changes (i.e., between pre-2005 and post-2005 observations) shown by Bronselaer et al. (2020), but in that study the high-latitude salinification is through the full depth of the water column, and not confined to near surface as in our estimate. These features in the observations are intriguing, potentially indicating freshening from ice shelf basal melt (Jacobs et al. 2002; Pauling et al. 2017; Bronselaer et al. 2020) and surface salinity changes due to ocean-sea ice feedbacks (Goosse and Zunz 2014; Haumann et al. 2016).

The freshwater input due to ice shelves/sheets is significantly less than the change in net precipitation-minus-evaporation over the Southern Ocean (Pauling et al. 2016), but is concentrated at the Antarctic coastline where buoyancy is dominated by haline (rather than thermal) effects, and so it may have a significant impact. Although further analysis is beyond the scope of this paper, it is important to address the fact that the freshening by ice sheets and shelves is only marginally included in the CMIP5 models, which do not have dynamic ice sheets (Naughten et al. 2018); instead, any surface mass balance due surplus precipitation-minus-evaporation over Antarctica is represented as a surface runoff (i.e., the dynamic component of ice mass loss is excluded). Thus, we would not expect close agreement between the models and observations on the Antarctic continental shelf. However, given the small volume of this feature relative to the fingerprint domain, the apparent coastal surface salinity changes are unlikely to significantly influence the detection and attribution results. We do note that ice shelf melt was included in SW18, by means of an added freshwater runoff at the Antarctic coast in excess of precipitation over the continent.

In summary, model temperature responses agree well with the observed change, with the exception of the near-surface waters in the sea ice zone, and suggest a GHG-forced warming that reaches all density classes in the Southern Ocean over this period. The salinity response is not so robust, and while in abyssal and highlatitude water masses this is likely due to inadequate representation of ocean-cryosphere interactions and deep-water formation processes (i.e., increased sea ice, freshening by ice shelf melt, shelf production of bottom waters, increased precipitation), even at lower latitudes there is a spread in model responses in the SAMW region. The models do, however, consistently show a freshening of AAIW. Overall, the simulated upper water column temperature and salinity responses are consistent with previous work using a large ensemble experimental approach (SW18) but also extend these patterns to the deep ocean.

\section{b. Detection and attribution results}

Optimal fingerprint results for both temperature and salinity are summarized in Fig. 4, which shows the best-fit scaling factor that matches the simulated forced response to observations, as well as $99 \%$ confidence interval around this best fit, estimated from the control simulations. The results clearly show a forced warming, with 9 of the 10 models indicating a detectable temperature response to All-forcings (i.e., scaling range not crossing 0). This appears to be largely a response to anthropogenic forcing; there is no attributable response to natural forcings, but a GHG signal is attributable in all of the six 
ALL
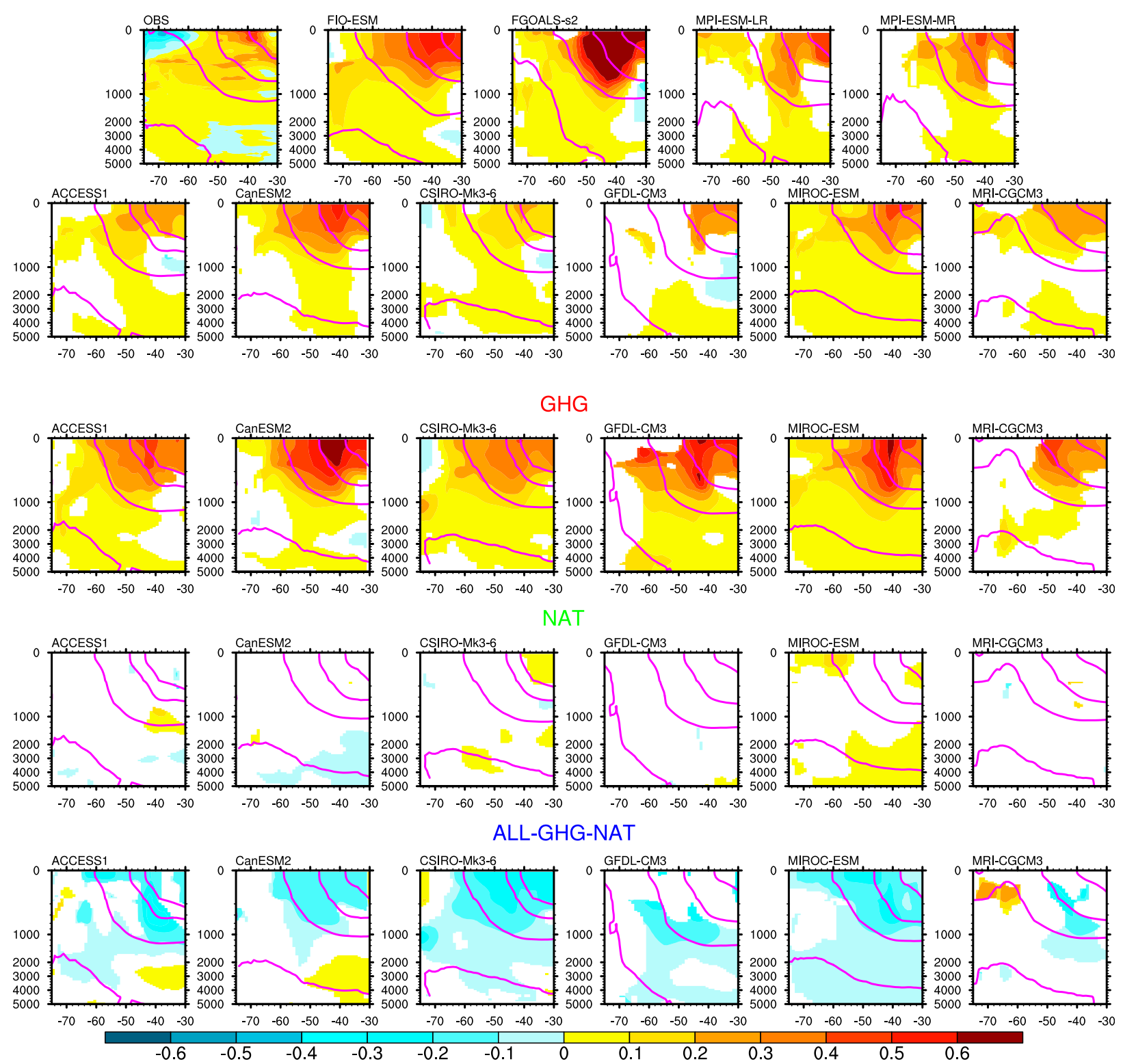

FIG. 2. Observed and simulated zonal mean potential temperature change $\left({ }^{\circ} \mathrm{C}\right)$ between the $1966-75$ and $1996-2005$ averaging periods, for All-forcings (ALL) and, where available, GHG-only (GHG), Natural-only (NAT), and the implied non-GHG anthropogenic response (ALL - GHG - NAT). Model patterns are averaged over all grid cells (i.e., represent a true zonal mean) and are averaged over all relevant ensemble members. Model differences are shaded only if the ensemble mean absolute difference is greater than $2 \sigma / N^{1 / 2}$, where $N$ is number of ensemble members and $\sigma$ is the model's standard deviation across piControl realizations. Magenta lines show the boundaries of (from lightest to densest) SAMW, AAIW, CDW, and AABW identified as described in the online supplemental material, averaged over the entire $40-\mathrm{yr}$ period.

models with individual forcing experiments. The response to non-GHG anthropogenic forcing is more model dependent, with only three of the six models indicating an attributable change. This result may be caused in part by the uncertainty of the pattern, which nominally includes multiple forcings (stratospheric ozone depletion and anthropogenic aerosols, assuming the impact of land use change is minimal), and by estimating the pattern as a residual from relatively few ensemble members. However, we also note that our result for CanESM2 is qualitatively consistent with SW18, who using the same model found an attributable temperature response to ozone depletion but not to anthropogenic aerosols. We therefore suggest that further investigation is required before the attribution of Southern Ocean temperature change to ozone depletion can be fully confirmed in light of this evidence. 
ALL

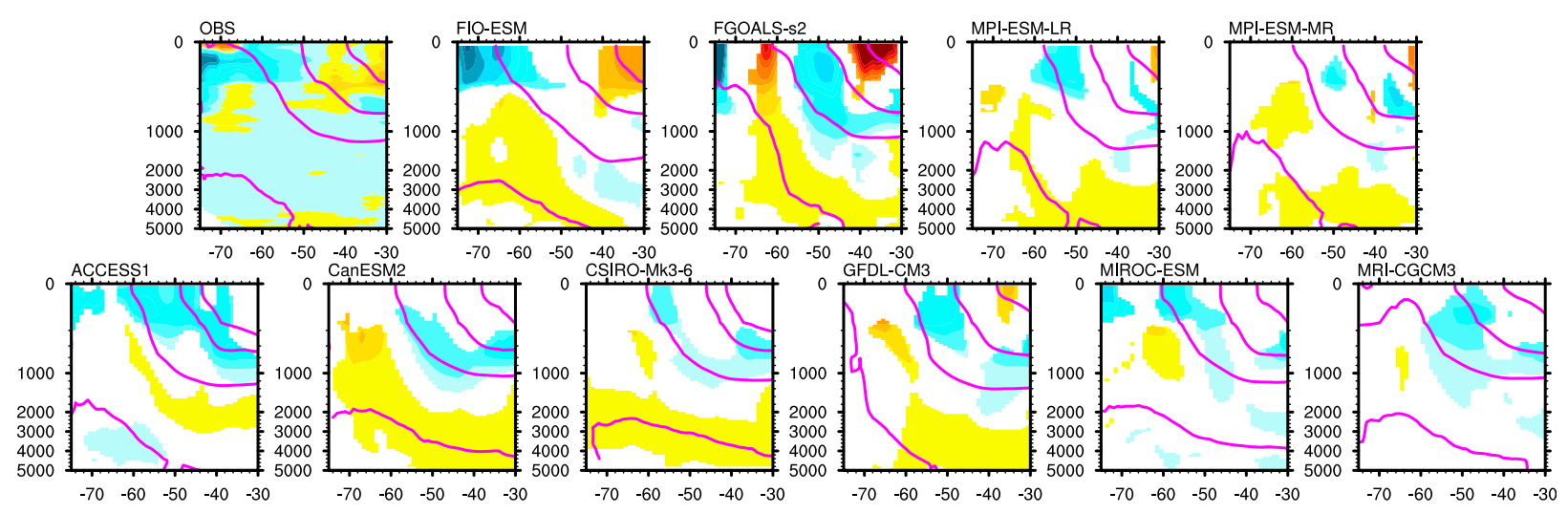

\section{GHG}
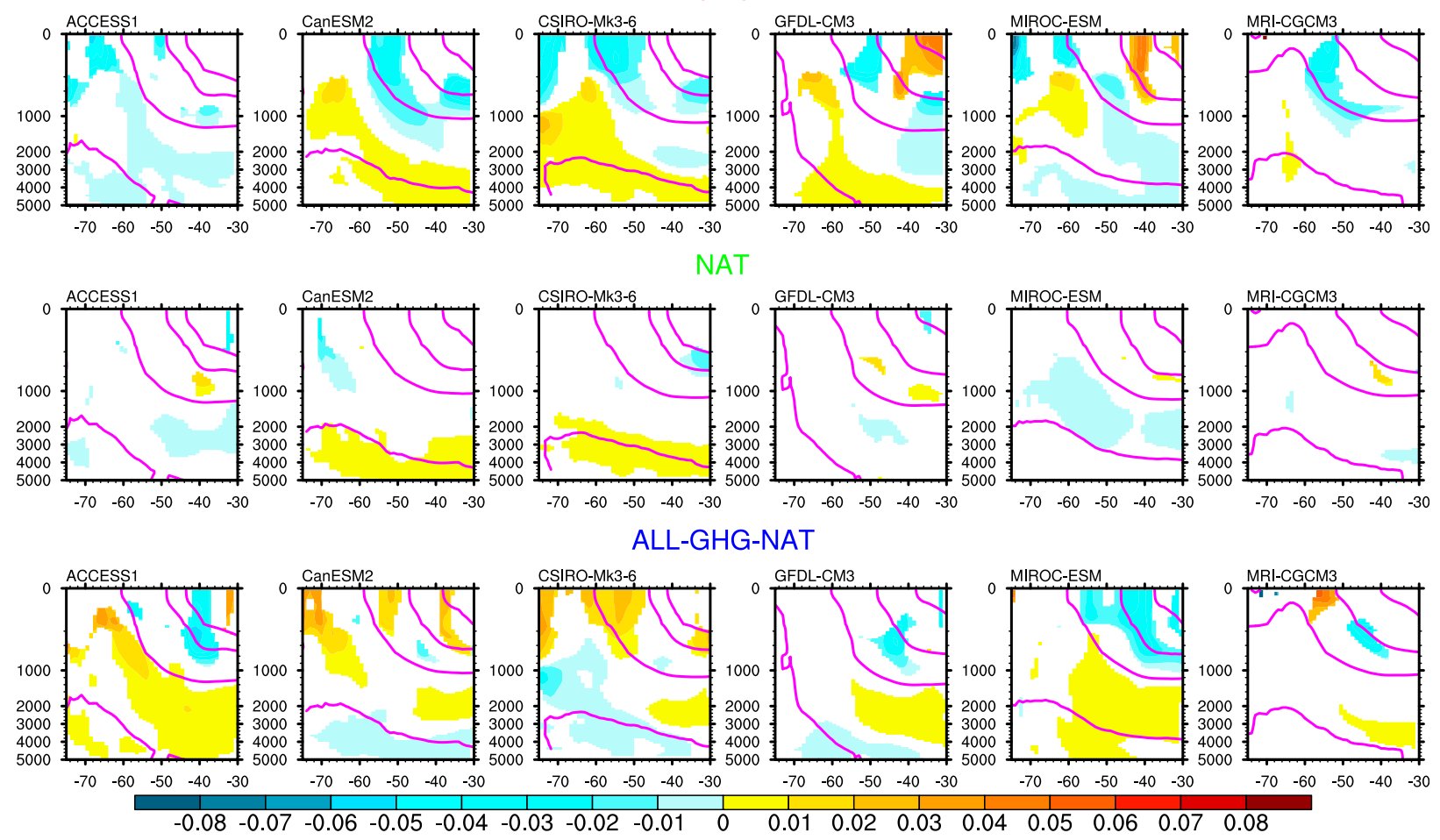

FIG. 3. As in Fig. 2, but for Absolute Salinity changes $\left(\mathrm{g} \mathrm{kg}^{-1}\right)$.

The salinity responses (Fig. 4b) are also broadly consistent with SW18, albeit not as robustly as for the observed warming. There is a detectable salinity response for 8 of 10 models, which seems to be partly attributable to GHG-forcing (4 of 6 models). Again, our results for CanESM2 are qualitatively consistent with SW18, with an attributable freshening of AAIW from GHG-forcing. Two models (CSIRO Mk3.6.0 and GFDL CM3) indicate an attributable salinity response to natural forcings, a result we regard with some skepticism. The best-fit scaling factors are large $(\beta>3.5$; recall that a value of approximately 1 suggests reasonable agreement between the model and observations), which suggests that the natural response is too weak in those models, but we cannot discount the possibility that salinity internal variability is also too weak, leading to underestimated confidence intervals. Two models also show an attributable salinity response to non-GHG anthropogenic forcings (GFDL CM3 and MIROC-ESM), which in Fig. 3 is characterized by a freshening of AAIW and increased salinity at midlatitudes in the CDW density range. We note that while ACCESS1 has similar elements in Fig. 3 (albeit with an increase in salinity in the CDW density range at higher latitudes), the response is not attributable for ACCESS1, diminishing our confidence in attribution of a non-GHG anthropogenic salinity change. However, this response may merit more detailed further analysis.

Figures 2 and 3 show that, while the strongest absolute changes are in the density range of SAMW/AAIW water 

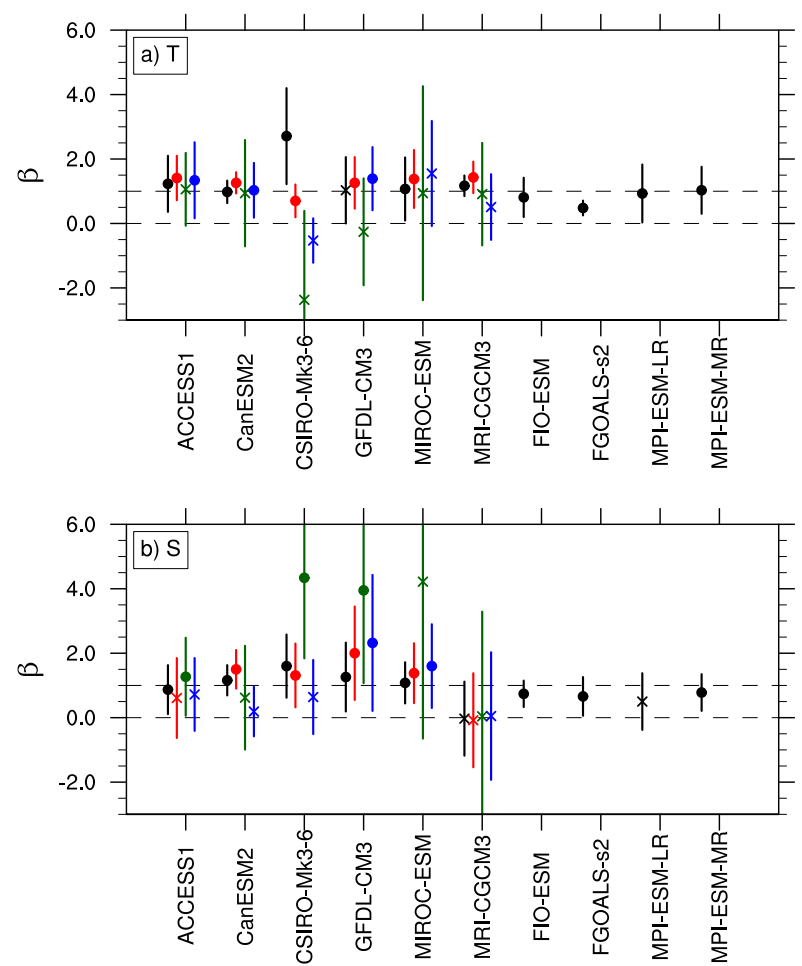

FIG. 4. Optimal fingerprinting scaling factors for (a) temperature and (b) salinity by model. Vertical lines show the $99 \%$ confidence interval for the control distribution of unforced pseudo observations; responses are detectable/attributable where this interval does not cross zero (shown by solid circle markers). All-forcings results are black; where available, GHG-only results are red; Natural forcings are green; non-GHG anthropogenic forcings are blue.

masses, the denser water masses also show simulated responses that are detectable in relation to simulated internal variability. The four water masses that we focus on in this paper (i.e., SAMW, AAIW, CDW, and AABW) have quite different formation locations and mechanisms, and it is therefore valuable to understand which of these water masses have attributable signals of anthropogenic change. By design, the optimal fingerprint method "weights" the analysis to regions/modes with the greatest signal-to-noise ratio (i.e., the strongest response in relation to local internal variability). This means that for our depth/latitude fingerprint, it is not immediately clear whether the attributable changes occur in the less dense waters (where the signal is greatest but so is the noise), the denser water masses (with reduced signal but also reduced noise), or both. To test this, we repeated the optimal fingerprint analysis separately for the SAMW/AAIW waters and the CDW/ AABW water masses (as defined by the isopycnals drawn in Figs. 2 and 3). The results are summarized in Fig. 5, restricting the analysis to the All-forcings response, which is available for all 10 models.

For the temperature response, there is a degree of model dependence. Four models indicate detectable warming at all density levels (ACCESS1, CanESM2, CSIRO Mk3.6.0, and FGOALS-s2); MPI-ESM-LR only has a detectable warming
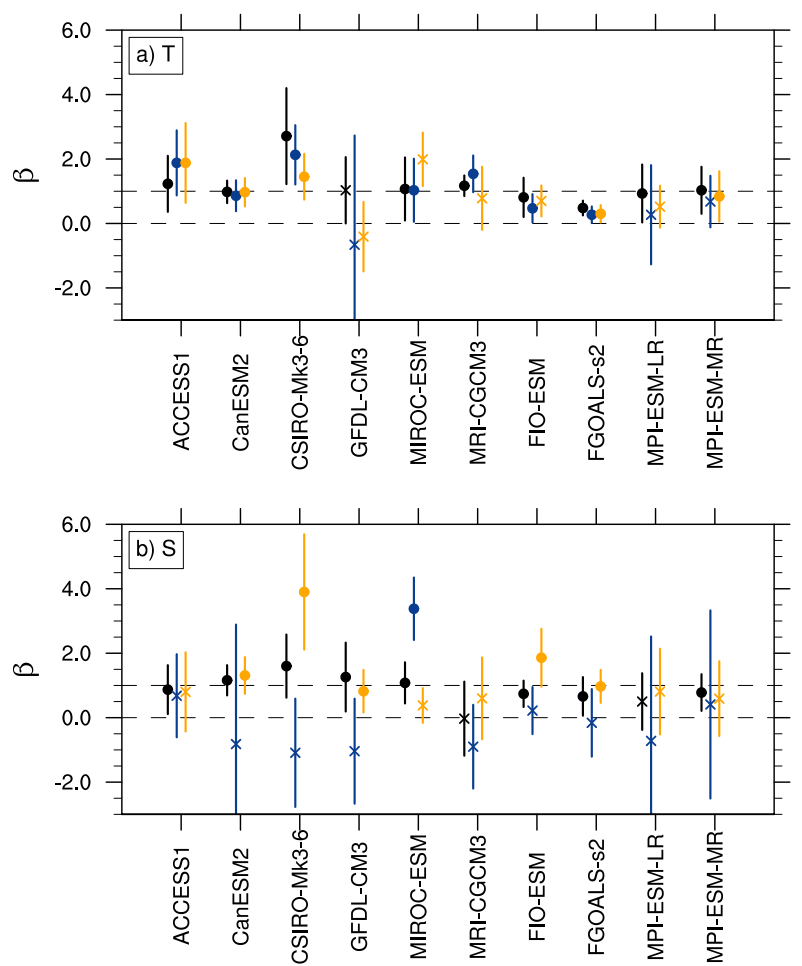

FIG. 5. Comparison of All-forcings optimal fingerprinting results for (a) temperature and (b) salinity, for difference density classes. All water masses are shown in black, lighter water masses (SAMW/ AAIW) are orange, and denser water masses (CDW/AABW) are blue. Solid circles indicate detectable signals; crosses show signals that are not detectable or that failed the Allen and Tett (1999) consistency test.

when all water masses are included; the detectable signal in MPI-ESM-MR seems to be in the shallower water masses; and there are three models where the detectable signal is in the denser but not the lighter water masses. Nine models have a detectable warming from their full-depth patterns (i.e., all but GFDL CM3). Of these nine, only one (MPI-ESM-MR) has a detectable signal in the lighter water masses (orange marker) but not in the denser waters; none of the other models has a warming that is detectable in - and only in - the lighter water masses. This implies that, even though the warming magnitude is greatest in the SAMW (Fig. 2), the denser water masses are an important part of the Southern Ocean detectable change and indicates an anthropogenic warming in the deep Southern Ocean.

For the salinity the reverse is true, albeit with some model dependence (Fig. 5b). Only one model indicates a detectable salinity change in the deeper water masses (MIROC-ESM), but for eight of the models a salinity change is detectable only if the lighter water masses are included. Furthermore, inspection of the response patterns in Fig. 3 indicates that this salinity change is dominated by the freshening of AAIW in response to GHG forcings.

These results must be interpreted with regard to the knowledge that global coupled models poorly represent the processes 
ALL
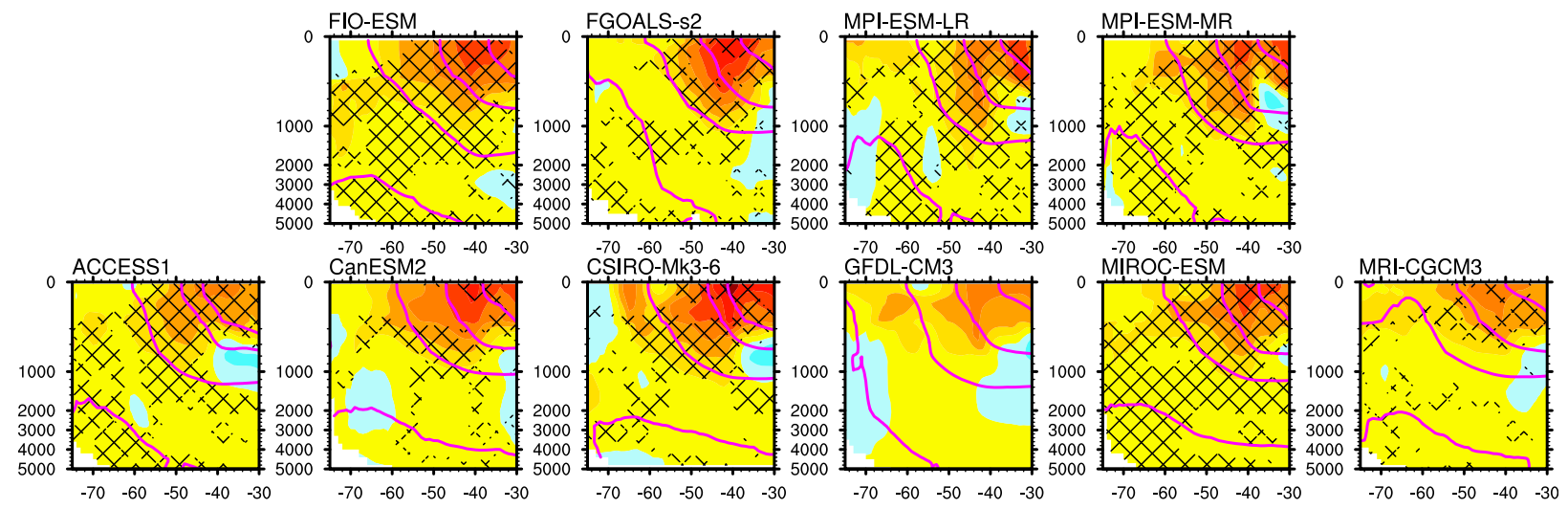

GHG
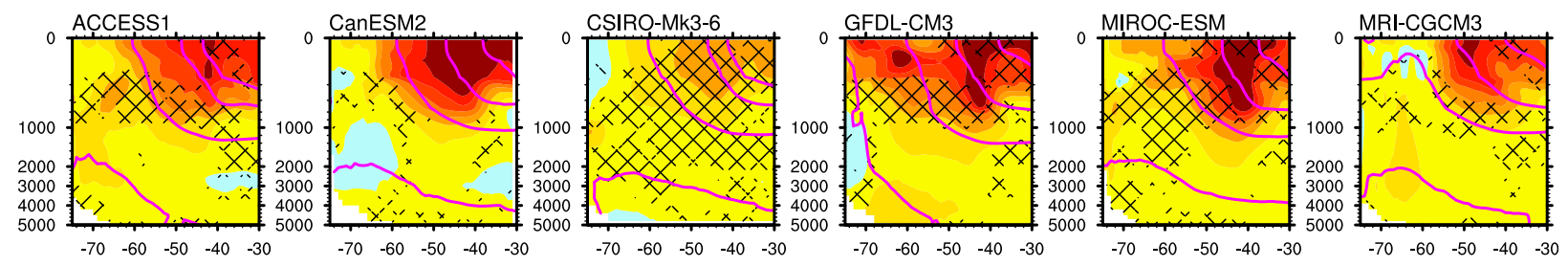

ALL-GHG-NAT

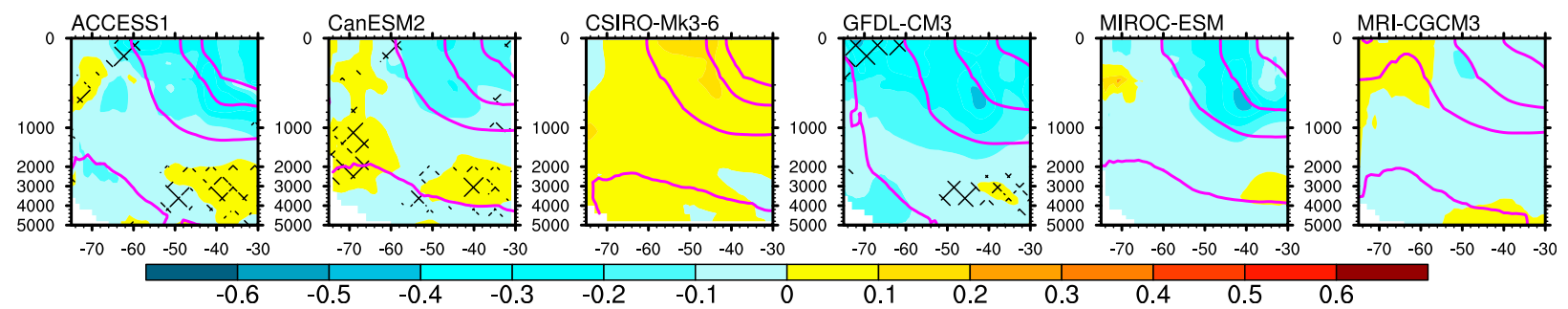

FIG. 6. As for Fig. 2, but simulated temperature change patterns have been scaled by the optimal fingerprint scaling factors shown in Fig. 4. (Observations and natural forcings are excluded.) Black hatching shows where the response is detectable and temperature change is within the range defined by scaling by the full range of confidence intervals shown in Fig. 4.

of AABW formation (Heuzé et al. 2015), and whether the observed warming and freshening of AABW (Purkey and Johnson 2013; van Wijk and Rintoul 2014) can be reliably detected. We suggest that the detectable deep warming is likely to be dominated by CDW since it represents a much larger ocean volume than $\mathrm{AABW}$, and there are very few profiles that include observations from the AABW density class. With respect to salinity, most (but not all) the models show a forced increase in salinity of AABW rather than a freshening, due possibly to incorrect model physics and/or the lack of freshening from ice sheet acceleration in the CMIP5 experiments. Currently, attribution of $\mathrm{AABW}$ changes is challenged by both the observing network and current modeling capability.
Further insight into the depth/latitude of the attributable signals may be gained by considering the scaled response (i.e., the responses in Figs. 2 and 3 multiplied by the scaling factors in Fig. 4) and comparing with the change estimated from observations. These are shown in Fig. 6 (for temperature) and Fig. 7 (for salinity), where hatching in each plot indicates both that the response is detectable/attributable (as shown by Fig. 4), and the observed change is within the range of the pattern scaled by the minimum and maximum scaling factors in the confidence interval shown in Fig. 4 (i.e., the range of uncertainty in the scaling factor due to internal variability); hatching therefore indicates specific regions where the observed change can be attributed to anthropogenic forcings. 

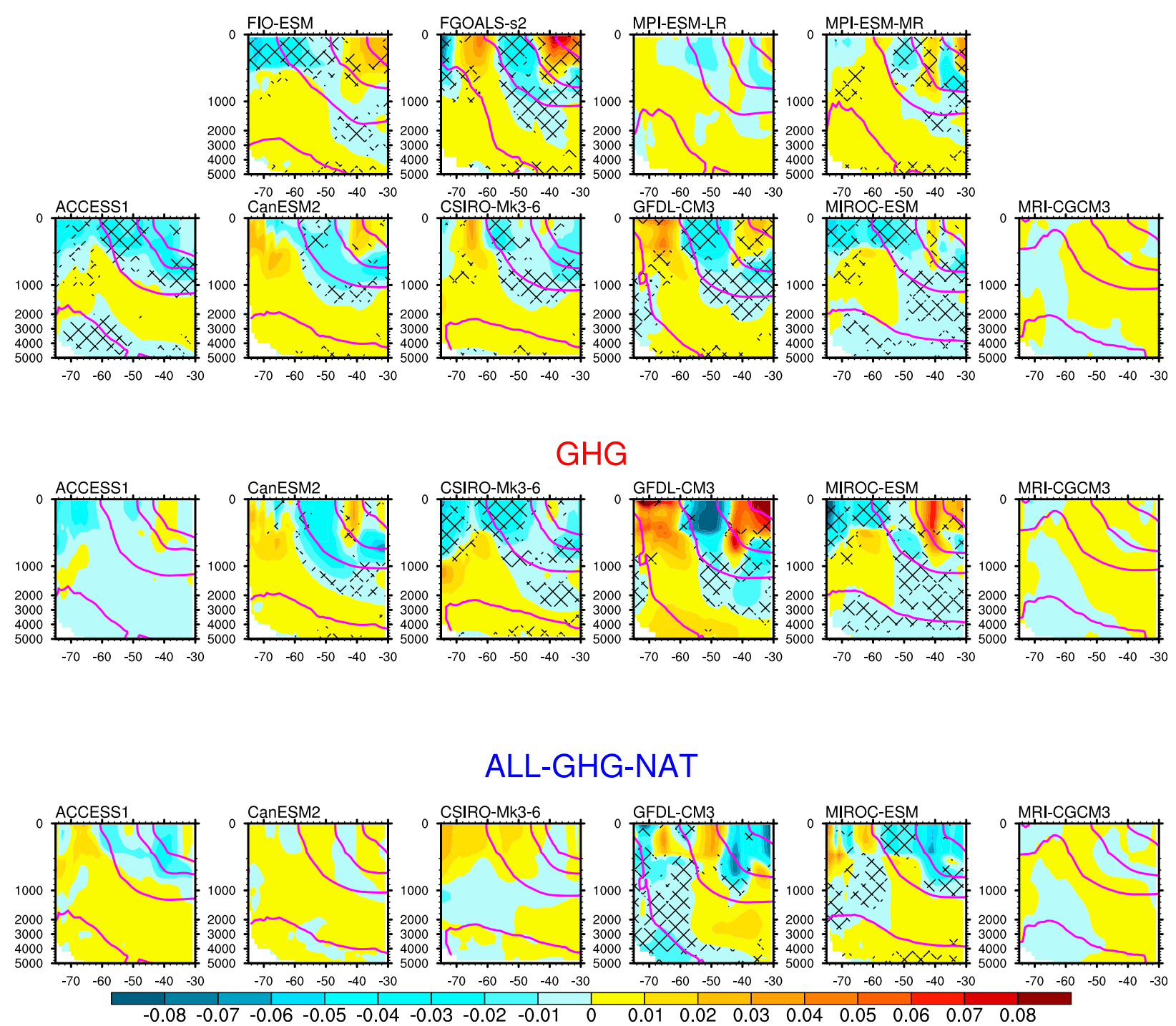

FIG. 7. As for Fig. 6 but for simulated salinity change patterns.

After scaling, the warming due to GHG is stronger than for the All-forcings case (Fig. 6), especially in the SAMW water mass, as it is for the unscaled patterns in Fig. 2. Agreement with the observed SAMW warming is better in the All-forcings pattern than the GHG-only pattern. This result suggests that while the non-GHG forcings (i.e., aerosols, ozone depletion, and natural forcings) are not robustly separable from internal variability, these forcings may have had a significant mitigating effect on anthropogenic warming in the Southern Ocean. Consistent with the analysis in Fig. 5a, Fig. 6 shows detectable CDW warming that is attributable GHG forcing, and to a lesser degree non-GHG anthropogenic forcing, including south of $60^{\circ} \mathrm{S}$ and deeper than $2000 \mathrm{~m}$, the domain limits of SW18. The salinity results (Fig. 7) are also consistent with the analysis in Fig. 5, clearly showing that the observed salinity change is largely characterized by a GHG-forced freshening of AAIW. Some models also indicate a detectable freshening of AABW (ACCESS1 and MIROC-ESM) but, as discussed, the poor representation of AABW formation in CMIP5 models limits our confidence in that result.

\section{Discussion and conclusions}

Our analysis shows that there has been a detectable warming in the Southern Ocean over the late twentieth century, largely attributable to anthropogenic greenhouse gases. The absolute warming signal is strongest in Subantarctic Mode and Antarctic Intermediate Waters, but we also show strong evidence of 
anthropogenic warming of denser water masses. Our analysis also indicates that non-GHG forcings may have somewhat mitigated the warming of Mode and Intermediate Waters. We also show detectable salinity changes, most clearly a greenhouse gas-forced freshening of Antarctic Intermediate Waters.

Our results are qualitatively consistent with SW18 and in particular we replicate the attributable GHG-forced changes in temperature and salinity using CanESM2. We also replicate an attributable response to non-GHG anthropogenic forcings (i.e., stratospheric ozone depletion, anthropogenic aerosols, and land use change) that is consistent with results from the CanESM2 model. However, our study shows that this result is model dependent, with the non-GHG anthropogenic forcing being attributable for only three of the six models used (Table 1), and therefore reducing our degree of confidence that there is a Southern Ocean salinity response to non-GHG anthropogenic forcing.

After scaling the model fingerprints, we show that the allforcings response agrees better with the observed changes than the GHG-only case, even though greenhouse gasses are undeniably the dominant forcing. This indicates that the GHG warming is reduced by non-GHG anthropogenic forcings. This result is consistent with studies of surface warming at global scales that show a greater warming under GHG-only forcings (Bindoff et al. 2013) than when other anthropogenic forcings are included.

A point of difference between this study and SW18 is that, because of the lack of single-forcing experiments in the CMIP5 dataset, we are unable to separate the response to individual forcings in the non-GHG anthropogenic response (i.e., landuse change, anthropogenic aerosols, and stratospheric ozone depletion), although we assume the impact of land-use change on the Southern Ocean to be minimal (Hansen et al. 2011; von Schuckmann et al. 2016). SW18 found an ozone-depletion forced warming in the upper $500 \mathrm{~m}$ at $40^{\circ}-60^{\circ} \mathrm{S}$ (i.e., the shallower layers of the AAIW/SAMW water masses), whereas our combined pattern from CanESM2 has a cooling in this region. This implies that the AAIW/SAMW cooling that is present in our combined pattern for most models is due to anthropogenic aerosols. This is physically consistent with the mitigation of GHG forcing that this combined fingerprint suggests, but we note that SW18 found aerosols not to have an attributable signal. We suggest that further multimodel analysis is required to robustly quantify the relative impacts of ozone depletion and anthropogenic aerosols on the Southern Ocean.

A further point of difference between our analysis and SW18 is that we include waters deeper than $2000 \mathrm{~m}$ and poleward of $60^{\circ} \mathrm{S}$. This extension to deeper waters robustly indicates a CDW warming that includes the high latitudes, even though the magnitude of warming is modest when compared with AAIW/SAMW. CDW is generally considered an "old" water mass with relatively little contact with the atmosphere in recent centuries, limiting the anthropogenic impact. However, hydrographic surveys of the Southern Ocean show a modest chlorofluorocarbon (CFC-11) signal in these waters (e.g., Orsi and Whitworth 2005), consistent with relatively recent surface ventilation and therefore an anthropogenic signal. This result has implications for future surface warming, since upwelling $\mathrm{CDW}$ is considered to reduce the surface impacts of GHG forcing at southern high latitudes (Armour et al. 2016); this reduction will be diminished as the upwelling water itself becomes warmer.

In a less robust manner than for the shallower water masses, some of the models indicate that the observed warming and freshening of AABW may be detectably outside the range of internal variability. This result is interesting but must be considered with caution, since CMIP5 models typically lack a good representation of $\mathrm{AABW}$ formation and transport processes (Heuzé et al. 2013, 2015; de Lavergne et al. 2014) and do not include ice-shelf cavities, which might also be important in setting AABW characteristics and changes (Lago and England 2019).

Confirmation of the more model-dependent results, in particular the emergence of stratospheric ozone depletion in the Southern Ocean, demands full analysis of the physical drivers in action under different combinations of climate forcings that is beyond the scope of this work. We note that by its ability to eliminate the confounding factor of internal variability, a single-model large ensemble framework is an invaluable tool to unravel these interactions, but multimodel analysis is also necessary to address the issue of model reliability. Our results clearly demonstrate that while there is rigorous evidence of anthropogenic change in the Southern Ocean, ongoing work is required to fully understand the contributions of the each forcing and the mechanisms of change.

Acknowledgments. The authors extend their gratitude to the two anonymous reviewers, whose constructive suggestions have improved this paper. WRH was supported in this work by the Australian Research Council Antarctic Gateway Partnership and both WRH and NLB by the Antarctic Climate and Ecosystems Cooperative Research Centre, and the Australian Government's Antarctic Science Collaboration Initiative Program (ASCI000002). Data analysis and visualization was performed using NCL (https://doi.org/10.5065/D6WD3XH5), and was undertaken with the assistance of resources and services from the National Computational Infrastructure (NCI), which is supported by the Australian Government. The authors acknowledge the World Climate Research Programme's Working Group on Coupled Modelling, which is responsible for CMIP, and we thank the climate modelling groups (listed in Table 1) for producing and making available their model output. Funding for Australia's contribution to CMIP5 came from the Natural Environment Science Program through its Earth System Science and Climate Change Hub, which also supported NLB's participation in this research.

Data availability statement. CMIP5 data used in this study are freely available from the Earth System Grid Federation (ESGF; https://esgf-node.llnl.gov/search/cmip5/). Observational temperature and salinity profiles are available from the NOAA/NODC World Ocean Database (https://www.nodc.noaa.gov/OC5/WOD/ pr_wod.html). All code, as well as any postprocessed data files derived from the primary sources, is available by request from the contributing author.

\section{REFERENCES}

Abernathey, R. P., I. Cerovecki, P. R. Holland, E. Newsom, M. Mazlo, and L. D. Talley, 2016: Water-mass transformation 
by sea ice in the upper branch of the Southern Ocean overturning. Nat. Geosci., 9, 596-601, https://doi.org/10.1038/ngeo2749.

Allen, M. R., and S. F. B. Tett, 1999: Checking for model consistency in optimal fingerprinting. Climate Dyn., 15, 419-434, https://doi.org/10.1007/s003820050291.

— fingerprinting, part I: Theory. Climate Dyn., 21, 477-491, https://doi.org/10.1007/s00382-003-0313-9.

Aoki, S., N. L. Bindoff, and J. A. Church, 2005: Interdecadal water mass changes in the Southern Ocean between $30^{\circ} \mathrm{E}$ and $160^{\circ}$ E. Geophys. Res. Lett., 32, L07607, https://doi.org/10.1029/ 2004GL022220.

Armour, K. C., J. Marshall, J. R. Scott, A. Donohoe, and E. R. Newsom, 2016: Southern Ocean warming delayed by circumpolar upwelling and equatorward transport. Nat. Geosci., 9, 549-554, https://doi.org/10.1038/ngeo2731.

Arora, V. K., and Coauthors, 2011: Carbon emission limits required to satisfy future representative concentration pathways of greenhouse gases. Geophys. Res. Lett., 38, L05805, https:// doi.org/10.1029/2010GL046270.

Banks, H. T., and N. L. Bindoff, 2003: Comparison of observed temperature and salinity changes in the Indo-Pacific with results from the coupled climate model HadCM3: Processes and mechanisms. J. Climate, 16, 156-166, https://doi.org/10.1175/ 1520-0442(2003)016<0156:COOTAS $>2.0$.CO;2.

Bao, Q., and Coauthors, 2013: The Flexible Global OceanAtmosphere-Land System Model, spectral version 2: FGOALSs2. Adv. Atmos. Sci., 30, 561-576, https://doi.org/10.1007/ s00376-012-2113-9.

Bi, D. H., and Coauthors, 2013: The ACCESS coupled model: Description, control climate and evaluation. Aust. Meteor. Oceanogr. J., 63, 41-64, https://doi.org/10.22499/2.6301.004.

Bilbao, R. A. F., J. M. Gregory, N. Bouttes, M. D. Palmer, and P. Stott, 2019: Attribution of ocean temperature change to anthropogenic and natural forcings using the temporal, vertical and geographical structure. Climate Dyn., 53, 5389-5413, https://doi.org/10.1007/s00382-019-04910-1.

Bindoff, N. L., and T. J. McDougall, 2000: Decadal changes along an Indian Ocean section at $32^{\circ} \mathrm{S}$ and their interpretation. J. Phys. Oceanogr., 30, 1207-1222, https://doi.org/10.1175/ 1520-0485(2000)030<1207:DCAAIO > 2.0.CO;2.

- , and Coauthors, 2013: Detection and attribution of climate change: From global to regional. Climate Change 2013: The Physical Science Basis, T. F. Stocker et al., Eds., Cambridge University Press, 867-952.

Bitz, C. M., and L. M. Polvani, 2012: Antarctic climate response to stratospheric ozone depletion in a fine resolution ocean climate model. Geophys. Res. Lett., 39, L20705, https://doi.org/ 10.1029/2012GL053393.

Boyer, T. P., S. Levitus, J. I. Antonov, R. A. Locarnini, and H. E. Garcia, 2005: Linear trends in salinity for the World Ocean, 1955-1998. Geophys. Res. Lett., 32, L01604, https://doi.org/ 10.1029/2004GL021791.

Bronselaer, B., and Coauthors, 2020: Importance of wind and meltwater for observed chemical and physical changes in the Southern Ocean. Nat. Geosci., 13, 35-42, https://doi.org/ 10.1038/s41561-019-0502-8.

Cowan, T., W. Cai, A. Purich, L. Rotstayn, and M. H. England, 2013: Forcing of anthropogenic aerosols on temperature trends of the sub-thermocline southern Indian Ocean. Sci. Rep., 3, 2245, https://doi.org/10.1038/srep02245.

de Lavergne, C., J. B. Palter, E. D. Galbraith, R. Bernardello, and I. Marinov, 2014: Cessation of deep convection in the open
Southern Ocean under anthropogenic climate change. Nat. Climate Change, 4, 278-282, https://doi.org/10.1038/ nclimate2132.

Durack, P. J., and S. E. Wijffels, 2010: Fifty-year trends in global ocean salinities and their relationship to broad-scale warming. J. Climate, 23, 4342-4362, https://doi.org/10.1175/2010 JCLI3377.1.

Fan, T. T., C. Deser, and D. P. Schneider, 2014: Recent Antarctic sea ice trends in the context of Southern Ocean surface climate variations since 1950. Geophys. Res. Lett., 41, 2419-2426, https://doi.org/10.1002/2014GL059239.

Frölicher, T. L., J. L. Sarmiento, D. J. Paynter, J. P. Dunne, J. P. Krasting, and M. Winton, 2015: Dominance of the Southern Ocean in anthropogenic carbon and heat uptake in CMIP5 models. J. Climate, 28, 862-886, https://doi.org/10.1175/JCLID-14-00117.1.

Fyfe, J. C., 2006: Southern Ocean warming due to human influence. Geophys. Res. Lett., 33, L19701, https://doi.org/10.1029/2006 GL027247.

Gao, L., S. R. Rintoul, and W. Yu, 2018: Recent wind-driven change in Subantarctic Mode Water and its impact on ocean heat storage. Nat. Climate Change, 8, 58-63, https://doi.org/ 10.1038/s41558-017-0022-8.

Gille, S. T., 2002: Warming of the Southern Ocean since the 1950s. Science, 295, 1275-1277, https://doi.org/10.1126/science.1065863.

Goosse, H., and V. Zunz, 2014: Decadal trends in the Antarctic sea ice extent ultimately controlled by ice-ocean feedback. Cryosphere, 8, 453-470, https://doi.org/10.5194/tc-8-453-2014.

Griffies, S. M., and Coauthors, 2011: The GFDL CM3 coupled climate model: Characteristics of the ocean and sea ice simulations. J. Climate, 24, 3520-3544, https://doi.org/10.1175/ 2011JCLI3964.1.

Hansen, J., M. Sato, P. Kharecha, and K. von Schuckmann, 2011: Earth's energy imbalance and implications. Atmos. Chem. Phys., 11, 13 421-13 449, https://doi.org/10.5194/acp-11-134212011.

Hasselmann, K., 1993: Optimal fingerprints for the detection of timedependent climate change. J. Climate, 6, 1957-1971, https:// doi.org/10.1175/1520-0442(1993)006<1957:OFFTDO>2.0. $\mathrm{CO} ; 2$.

Haumann, F. A., N. Gruber, M. Munnich, I. Frenger, and S. Kern, 2016: Sea-ice transport driving Southern Ocean salinity and its recent trends. Nature, 537, 89-92, https://doi.org/10.1038/ nature19101.

Hegerl, G. C., O. Hoegh-Guldberg, G. Casassa, M. Hoerling, S. Kovats, C. Parmesan, and P. Stott, 2009: Good practice guidance paper on detection and attribution related to anthropogenic climate change. IPCC Expert Meeting on Detecton and Attribution Related to Anthropogenic Climate Change, Geneva, Switzerland, Intergovernmental Panel on Climate Change, 8 pp.

Heuzé, C., K. J. Heywood, D. P. Stevens, and J. K. Ridley, 2013: Southern Ocean bottom water characteristics in CMIP5 models. Geophysical Research Letters, 40, 1409-1414, https:// doi.org/10.1002/grl.50287.

,,--- , and $—, 2015$ : Changes in global ocean bottom properties and volume transports in CMIP5 models under climate change scenarios. J. Climate, 28, 2917-2944, https:// doi.org/10.1175/JCLI-D-14-00381.1.

Hobbs, W., M. D. Palmer, and D. Monselesan, 2016a: An energy conservation analysis of ocean drift in the CMIP5 global coupled models. J. Climate, 29, 1639-1653, https://doi.org/ 10.1175/JCLI-D-15-0477.1. 
, R. Massom, S. Stammerjohn, P. Reid, G. D. Williams, and W. N. Meier, 2016b: A review of recent changes in Southern Ocean sea ice, their drivers and forcings. Global Planet. Change, 143, 228-250, https://doi.org/10.1016/j.gloplacha.2016.06.008.

IOC, SCOR, and IAPSO, 2010: The International Thermodynamic Equation of Seawater-2010: Calculation and use of thermodynamic properties. Intergovernmental Oceanographic Commission, Manuals and Guides No. 56, UNESCO (English), 196 pp.

Jacobs, S. S., C. F. Giulivi, and P. A. Mele, 2002: Freshening of the Ross Sea during the late 20th century. Science, 297, 386-389, https://doi.org/10.1126/science.1069574.

Jeffrey, S., and Coauthors, 2013: Australia's CMIP5 submission using the CSIRO-Mk3.6 model. Aust. Meteor. Oceanogr. J., 63, 1-13, https://doi.org/10.22499/2.6301.001.

Jungclaus, J. H., and Coauthors, 2013: Characteristics of the ocean simulations in the Max Planck Institute Ocean Model (MPIOM) the ocean component of the MPI-Earth system model. J. Adv. Model. Earth Syst., 5, 422-446, https://doi.org/ 10.1002/jame.20023.

Knutti, R., D. Masson, and A. Gettelman, 2013: Climate model genealogy: Generation CMIP5 and how we got there. Geophys. Res. Lett., 40, 1194-1199, https://doi.org/10.1002/grl.50256.

Lago, V., and M. H. England, 2019: Projected slowdown of Antarctic Bottom Water formation in response to amplified meltwater contributions. J. Climate, 32, 6319-6335, https:// doi.org/10.1175/JCLI-D-18-0622.1.

Marshall, J., and K. Speer, 2012: Closure of the meridional overturning circulation through Southern Ocean upwelling. Nat. Geosci., 5, 171-180, https://doi.org/10.1038/ngeo1391.

—, K. C. Armour, J. R. Scott, Y. Kostov, U. Hausmann, D. Ferreira, T. G. Shepherd and C. M. Bitz, 2014: The ocean's role in polar climate change: Asymmetric Arctic and Antarctic responses to greenhouse gas and ozone forcing. Philos. Trans. Roy. Soc., 372A, 20130040, https://doi.org/10.1098/rsta.2013.0040.

Mazloff, M. R., P. Heimbach, and C. Wunsch, 2010: An eddypermitting Southern Ocean state estimate. J. Phys. Oceanogr., 40, 880-899, https://doi.org/10.1175/2009JPO4236.1.

Meijers, A. J. S., N. L. Bindoff, and S. R. Rintoul, 2011: Frontal movements and property fluxes: Contributions to heat and freshwater trends in the Southern Ocean. J. Geophys. Res., 116, C08024, https://doi.org/10.1029/2010JC006832.

Monselesan, D., T. J. O'Kane, J. S. Risbey, and J. A. Church, 2015: Internal climate memory in observations and models. Geophys. Res. Lett., 42, 1232-1242, https://doi.org/10.1002/2014GL062765.

Morrison, A., T. L. Frolicher, and J. L. Sarmiento, 2015: Upwelling in the Southern Ocean. Phys. Today, 68, 27-32, https://doi.org/ 10.1063/PT.3.2654.

Naughten, K. A., K. J. Meissner, B. K. Galton-Fenzi, M. H. England, R. Timmermann, and H. H. Hellmer, 2018: Future projections of Antarctic ice shelf melting based on CMIP5 scenarios. J. Climate, 31, 5243-5261, https://doi.org/10.1175/ JCLI-D-17-0854.1.

Orsi, A. H., and T. Whitworth III, 2005: Southern Ocean. Vol. 1, Hydrographic Atlas of the World Ocean Circulation Experiment (WOCE), M. Sparrow, P. Chapman, and J. Gould, Eds., International WOCE Project Office, https://doi.org/ 10.21976/C6BC78.

— G. G. Johnson, and J. L. Bullister, 1999: Circulation, mixing, and production of Antarctic Bottom Water. Prog. Oceanogr., 43, 55-109, https://doi.org/10.1016/S0079-6611(99)00004-X.

Pauling, A. G., C. M. Bitz, I. J. Smith, and P. J. Langhorne, 2016: The response of the Southern Ocean and Antarctic Sea ice to freshwater from ice shelves in an Earth system model.
J. Climate, 29, 1655-1672, https://doi.org/10.1175/JCLI-D-150501.1.

- I. J. Smith, P. J. Langhorne, and C. M. Bitz, 2017: Timedependent freshwater input from ice shelves: Impacts on Antarctic Sea ice and the Southern Ocean in an Earth system model. Geophys. Res. Lett., 44, 10 454-10 461, https://doi.org/ 10.1002/2017GL075017.

Pellichero, V., J.-B. Sallée, C. C. Chapman, and S. M. Downes, 2018: The Southern Ocean meridional overturning in the seaice sector is driven by freshwater fluxes. Nat. Commun., 9, 1789, https://doi.org/10.1038/s41467-018-04101-2.

Polvani, L. M., and K. L. Smith, 2013: Can natural variability explain observed Antarctic sea ice trends? New modeling evidence from CMIP5. Geophys. Res. Lett., 40, 3195-3199, https://doi.org/10.1002/grl.50578.

Previdi, M., and L. M. Polvani, 2014: Climate system response to stratospheric ozone depletion and recovery. Quart. J. Roy. Meteor. Soc., 140, 2401-2419, https://doi.org/10.1002/qj.2330.

Purkey, S. G., and G. C. Johnson, 2013: Antarctic Bottom Water warming and freshening: Contributions to sea level rise, ocean freshwater budgets, and global heat gain. J. Climate, 26, 61056122, https://doi.org/10.1175/JCLI-D-12-00834.1.

,-- , and D. P. Chambers, 2014: Relative contributions of ocean mass and deep steric changes to sea level rise between 1993 and 2013. J. Geophys. Res. Oceans, 119, 7509-7522, https://doi.org/10.1002/2014JC010180.

Qiao, F. L., Z. Y. Song, Y. Bao, Y. J. Song, Q. Shu, C. J. Huang, and W. Zhao, 2013: Development and evaluation of an Earth system model with surface gravity waves. J. Geophys. Res. Oceans, 118, 4514-4524, https://doi.org/10.1002/jgrc.20327.

Ridgway, K. R., J. R. Dunn, and J. L. Wilkin, 2002: Ocean interpolation by four-dimensional least squares-Application to the waters around Australia. J. Atmos. Oceanic Technol., 19, 1357-1375, https://doi.org/10.1175/1520-0426(2002)019<1357: OIBFDW $>2.0 . \mathrm{CO} ; 2$.

Rintoul, S., and J. Church, 2002: The Southern Ocean's global reach: A crucial cog in Earth's heat engine. Aust. Antarct. Mag., 4, 2-4, https://www.antarctica.gov.au/magazine/issue-4spring-2002/feature2/the-southern-oceans-global-reach/.

— Ocean circulation. Ocean Circulation and Climate: A 21st Century Perspective, 2nd ed. G. Siedler et al., Eds., Elsevier Science, 471-492.

Roemmich, D., and J. Gilson, 2009: The 2004-2008 mean and annual cycle of temperature, salinity, and steric height in the global ocean from the Argo Program. Prog. Oceanogr., 82, 81100, https://doi.org/10.1016/j.pocean.2009.03.004.

- J. Church, J. Gilson, D. Monselesan, P. Sutton, and S. Wijffels, 2015: Unabated planetary warming and its ocean structure since 2006. Nat. Climate Change, 5, 240-245, https:// doi.org/10.1038/nclimate2513.

Sallée, J. B., R. J. Matear, S. R. Rintoul, and A. Lenton, 2012: Localized subduction of anthropogenic carbon dioxide in the Southern Hemisphere oceans. Nat. Geosci., 5, 579-584, https:// doi.org/10.1038/ngeo1523.

— E. Shuckburgh, N. Bruneau, A. J. S. Meijers, T. J. Bracegirdle, Z. Wang, and T. Roy, 2013: Assessment of Southern Ocean water mass circulation and characteristics in CMIP5 models: Historical bias and forcing response. J. Geophys. Res. Oceans, 118, 1830-1844, https://doi.org/10.1002/jgrc.20135.

Schmidtko, S., K. J. Heywood, A. F. Thompson, and S. Aoki, 2014: Multidecadal warming of Antarctic waters. Science, 346, 12271231, https://doi.org/10.1126/science.1256117. 
Swart, N. C., S. T. Gille, J. C. Fyfe, and N. P. Gillett, 2018: Recent Southern Ocean warming and freshening driven by greenhouse gas emissions and ozone depletion. Nat. Geosci., 11, 836-841, https://doi.org/10.1038/s41561-018-0226-1.

Tamsitt, V., and Coauthors, 2017: Spiraling pathways of global deep waters to the surface of the Southern Ocean. Nat. Commun., 8, 172, https://doi.org/10.1038/s41467-017-00197-0.

Taylor, K. E., R. J. Stouffer, and G. A. Meehl, 2012: An overview of CMIP5 and the experiment design. Bull. Amer. Meteor. Soc., 93, 485-498, https://doi.org/10.1175/BAMS-D-11-00094.1.

Tokarska, K. B., G. C. Hegerl, A. P. Schurer, A. Ribes, and J. T. Fasullo, 2019: Quantifying human contributions to past and future ocean warming and thermosteric sea level rise. Environ. Res. Lett., 14, 074020, https://doi.org/10.1088/17489326/ab23c1.

van Wijk, E. M., and S. R. Rintoul, 2014: Freshening drives contraction of Antarctic Bottom Water in the Australian Antarctic basin. Geophys. Res. Lett., 41, 1657-1664, https:// doi.org/10.1002/2013GL058921.

von Schuckmann, K., and Coauthors, 2016: An imperative to monitor Earth's energy imbalance. Nat. Climate
Change, 6, 138-144, https://doi.org/10.1038/nclimate 2876.

Watanabe, S., and Coauthors, 2011: MIROC-ESM 2010: Model description and basic results of CMIP5-20c3m experiments. Geosci. Model Dev., 4, 845-872, https://doi.org/10.5194/gmd-4845-2011.

Wijffels, S. E., D. Roemmich, D. Monselesan, J. A. Church, and J. Gilson, 2016: Ocean temperatures chronicle the ongoing warming of Earth. Nat. Climate Change, 6, 116-118, https:// doi.org/10.1038/nclimate2924.

Wong, A. P. S., N. L. Bindoff, and J. A. Church, 1999: Large-scale freshening of intermediate waters in the Pacific and Indian Oceans. Nature, 400, 440-443, https://doi.org/10.1038/22733.

Yukimoto, S., and Coauthors, 2012: A new global climate model of the Meteorological Research Institute: MRI-CGCM3-Model description and basic performance. J. Meteor. Soc. Japan, 90A, 23-64, https://doi.org/10.2151/jmsj.2012-A02.

Zunz, V., H. Goosse, and F. Massonnet, 2013: How does internal variability influence the ability of CMIP5 models to reproduce the recent trend in Southern Ocean sea ice extent? Cryosphere, 7, 451-468, https://doi.org/10.5194/tc-7-451-2013. 